\title{
Response to "Letter to the Editor: 'Melt rupture unleashed by few chain scission events in fully stretched strands'” [J. Rheol. 63, 105 (2018)]
}

Wagner, Manfred H.; Narimissa, Esmaeil; Huang, Qian

Published in:

Journal of Rheology

Link to article, DOI:

$10.1122 / 1.5087431$

Publication date:

2019

Document Version

Publisher's PDF, also known as Version of record

Link back to DTU Orbit

Citation (APA):

Wagner, M. H., Narimissa, E., \& Huang, Q. (2019). Response to "Letter to the Editor: 'Melt rupture unleashed by few chain scission events in fully stretched strands'” [J. Rheol. 63, 105 (2018)]. Journal of Rheology, 63(3), 419421. https://doi.org/10.1122/1.5087431

\section{General rights}

Copyright and moral rights for the publications made accessible in the public portal are retained by the authors and/or other copyright owners and it is a condition of accessing publications that users recognise and abide by the legal requirements associated with these rights.

- Users may download and print one copy of any publication from the public portal for the purpose of private study or research.

- You may not further distribute the material or use it for any profit-making activity or commercial gain

- You may freely distribute the URL identifying the publication in the public portal 


\section{Response to "Letter to the Editor: 'Melt rupture unleashed by few chain scission events in fully stretched strands'” [J. Rheol. 63, 105 (2018)]}

Manfred H. Wagner, Esmaeil Narimissa, and Qian Huang

Citation: Journal of Rheology 63, 419 (2019); doi: 10.1122/1.5087431

View online: https://doi.org/10.1122/1.5087431

View Table of Contents: https://sor.scitation.org/toc/jor/63/3

Published by the The Society of Rheology

\section{ARTICLES YOU MAY BE INTERESTED IN}

Nonlinear rheology of polydisperse blends of entangled linear polymers: Rolie-Double-Poly models Journal of Rheology 63, 71 (2019); https://doi.org/10.1122/1.5052320

Letter to the Editor: Melt rupture unleashed by few chain scission events in fully stretched strands Journal of Rheology 63, 105 (2019); https://doi.org/10.1122/1.5054655

Equibiaxial elongational rheology of entangled polystyrene melts

Journal of Rheology 63, 157 (2019); https://doi.org/10.1122/1.5062161

The yield normal stress

Journal of Rheology 63, 285 (2019); https://doi.org/10.1122/1.5063796

Effect of intermolecular interactions on the viscoelastic behavior of unentangled polyamide melts Journal of Rheology 63, 377 (2019); https://doi.org/10.1122/1.5060713

From elastic deformation to flow in tempered chocolate

Journal of Rheology 62, 1187 (2018); https://doi.org/10.1122/1.5038253

Master your flow

with the MCR Rheometer series
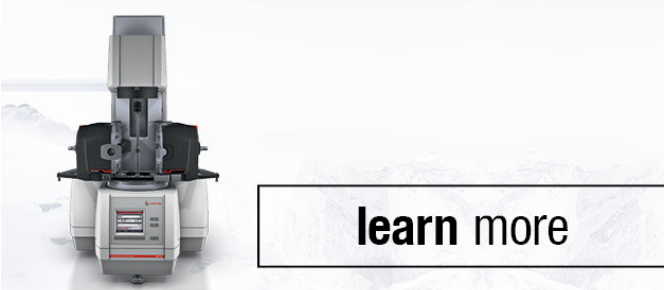
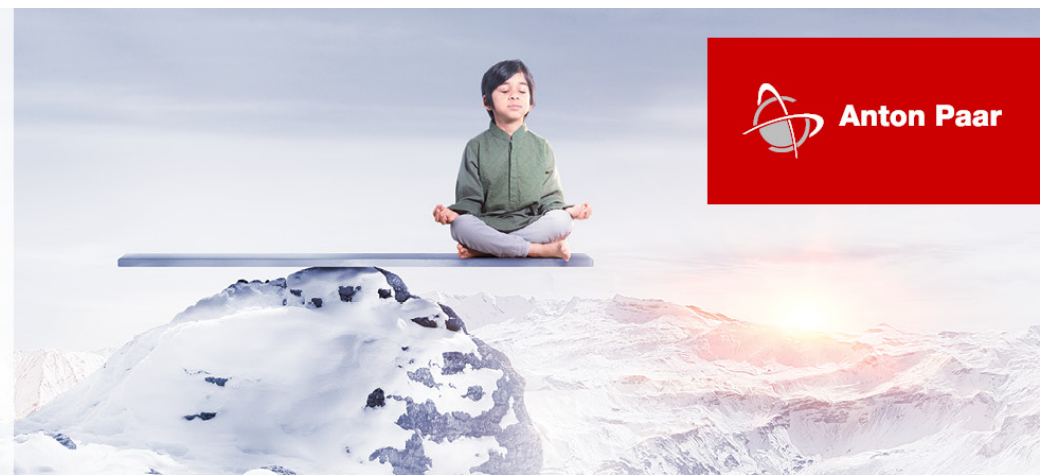


\title{
Response to "Letter to the Editor: 'Melt rupture unleashed by few chain scission events in fully stretched strands"' [J. Rheol. 63, 105 (2018)]
}

\author{
Manfred H. Wagner, ${ }^{1}$ Esmaeil Narimissa, ${ }^{2,3}$ and Qian Huang ${ }^{4}$ \\ ${ }^{1}$ Polymer Engineering / Polymer Physics, Berlin Institute of Technology (TU Berlin), Ernst-Reuter-Platz 1, \\ 10587 Berlin, Germany \\ ${ }^{2}$ Department of Chemical Engineering, Technion-Israel Institute of Technology (IIT), Technion City, Haifa 32000, \\ Israel \\ ${ }^{3}$ Department of Chemical Engineering, Guangdong Technion-Israel Institute of Technology (GTIIT), Shantou 515063, \\ China \\ ${ }^{4}$ Department of Chemical and Biochemical Engineering, Technical University of Denmark, 2800 Kongens Lyngby, \\ Denmark
}

(Received 1 January 2019; final revision received 5 March 2019; published 4 April 2019)

\begin{abstract}
In a recent Letter to the Editor by Wang [J. Rheol. 63, 105-107 (2018)], the entropic fracture hypothesis for cohesive fracture of polymer solutions and melts proposed by Wagner et al. [J. Rheol. 62, 221-233 (2018)] is questioned. We respond to several statements made by Wang. (C) 2019 The Society of Rheology. https://doi.org/10.1122/1.5087431
\end{abstract}

In his Letter to the Editor, Wang [1] advanced several arguments against the entropic fracture hypothesis of Wagner et al. [2], which we discuss in the following.

Wang [1] expressed his concern that the filament stretching rheometer (FSR) does not prescribe a homogeneous extensional strain field and that the data from FSR should not be compared with theoretical calculations that are based on the assumption of homogeneous extension. However, the FSR concept as developed by Hassager and co-workers does not rely on homogeneous deformation throughout the sample. Rather, during elongation, the location of the minimum diameter in the circular sample is predictably placed in the middle of the extending filament, thereby creating the symmetry plane, where the laser sheet is located [3]. In this midsection plane, the filament diameter and thereby the strain is measured at controlled values of the local Hencky strain rate. As the force at every vertical position along the filament is the same, the elongational stress in the symmetry plane, where the filament diameter is measured and controlled, can be determined from the force measurement. The material outside of the symmetry plane merely acts as a soft grip on the material under investigation in much the same way as the ends of a dogbone sample in tensile testing of solids [4].

As discussed in our paper [2], using a commercially available filament stretching rheometer (VADER 1000, Rheo Filament ApS), substantial progress in detailed experimental analysis of the fracture process of polymeric liquids has recently been made by Huang et al. [5] and Huang and Hassager [6] on well characterized monodisperse polystyrenes dispersed in oligomeric styrene. By measuring and controlling the local diameter at the midsection of the filament during elongation, the true Hencky strain and the strain rate of the polymeric material located at the midsection of the filament are known, while from the global deformation of the sample such as in rheometers of the Vinogradov, Münstedt, RME, EVF, or SER type, only nominal values of strain and strain rate can be obtained. Huang and Hassager showed [6] that when true Hencky strain rates are utilized rather than nominal Hencky rates, the four zones in the Malkin-Petrie plot are reduced to just two states: liquid and solid, and a clear distinction exists between liquid (infinite steady-state elongation) behavior and solid (fracture) behavior, which constitutes a major breakthrough in the unambiguous experimental identification of cohesive failure of polymeric liquids. This is in contrast to the measurements done by using SER presented in Fig. 1 of the Letter [1], where without highspeed optical control, it is very difficult to distinguish between ductile failure (necking) and cohesive fracture. Our entropic fracture hypothesis [2] is based on the cohesive fracture data of Huang et al. [5] and Huang and Hassager [6].

Wang [1] expressed his concern that to make the "entropic fracture" idea agree with the experimental data, idealized modeling was carried out in [2] by calculation of the molecular stretching function $f$ in the absence of any explicit consideration of chain entanglement and disentanglement. $\mathrm{He}$ suspects that affine deformation may have been involved in the model calculation, and he sees a "severe internal inconsistency" in the fact that a critical molecular stretch of $f_{c}=5$ or 6 is reported, while the experimental data in Figs. 1, 2, and 8 of [2] show Hencky strains at rupture of either around or beyond a Hencky strain $\varepsilon=2.5$, i.e., a macroscopic stretch ratio $\lambda>12$, which is substantially larger than $f_{c}$. In response, we recall that following Pearson et al. [7], average affine deformation of the chains is assumed in [2], and the evolution equation for the molecular stretch $f$ in the elastic limit (i.e., without stretch relaxation or constraint release effects) is 
expressed as

$$
\frac{\partial f}{\partial t}=f(\mathbf{K}: \mathbf{S})
$$

with $\mathbf{K}$ being the velocity gradient tensor and $\mathbf{S}$ being the second order orientation tensor. The analytical solution of Eq. (1) is given in [2] in terms of Hencky strain $\varepsilon$ and is presented here in terms of macroscopic stretch ratio $\lambda$,

$$
f=\exp \left[\frac{1}{\sqrt{\lambda^{3}-1}} \tan ^{-1}\left(\sqrt{\lambda^{3}-1}\right)+\ln (\lambda)-1\right],
$$

which reduces for $\lambda \gg 1$ to

$$
f \cong e^{-1} \lambda \cong 0.37 \lambda
$$

In agreement with experimental evidence, a critical molecular stretch of $f_{c}=6$ corresponds to $\lambda=16$ or Hencky strain $\varepsilon=2.8$. We further note that in the elastic limit, the true stress $\sigma_{c}$ at rupture increases with deformation as

$$
\sigma_{c}=5 G_{N}^{0} \varphi^{2} f_{c}^{2},
$$

with $G_{N}^{0}$ being the plateau modulus of the melt and $\varphi$ being the polymer volume fraction, again in agreement with experimental evidence (see, e.g., Figs. 5 and 7 in [2]). We also note that in the case of cross-linked rubbers, it is well known that stress does not increase according to the neo-Hookean model, and therefore, it is not surprising that the engineering stress of SBR1M, as shown in the inset of Fig. 1 of the Letter [1], does not follow the affine deformation hypothesis.

Wang [1] expressed his concern that the entropy scaling argument leading to the expression for the entropic free energy of an entanglement segment $w_{s}$ is itself questionable as it would suggest the chain scission event to be temperature independent: $\tau=\tau_{0} \exp \left(-w_{s} / k_{B} T\right)=\tau_{0} \exp \left(-3 f^{2}\right)$, and that such temperature independence contradicts the infrared spectroscopic study [8] that the bond scission is temperature sensitive. We note that $\tau$ is indeed temperature dependent due to the prefactor $\tau_{0}=\left(1 / \omega_{t h}\right) \exp \left(U / k_{B} T\right)$, which depends on the temperature dependent thermal fluctuation frequency $\omega_{\text {th }}=10^{10}-10^{12} \mathrm{~s}^{-1}$ as well as on the temperature dependent exponential factor $\exp (U / k T)$ (with $U$ being the bond energy of a carbon-carbon bond).

Wang [1] insists that although he does not have a theory to show how entanglements lock up during fast melt extension, it seems reasonable that the entanglement strands are under high tension in a fully stretched state at break. Unfortunately, he cannot be quantitative currently because there is no reliable quantitative theoretical description of what chain entanglement is and how it responds to fast continuous deformation. In [2], we have made an estimation of the critical stress $\sigma_{c}$ needed to rupture the chains according to the enthalpic fracture hypothesis, i.e., assuming fully stretched and oriented chain segments,

$$
\sigma_{c} \cong v F_{c} b \lambda_{m} \cong \frac{G_{N}^{0} \varphi^{2}}{k T} F_{c} b \lambda_{m}
$$

With the bond length $b=1.48 \mathrm{~nm}$ for PS and the rupture force $F_{c}=4 \times 10^{-9} \mathrm{~N}$ of a C-C bond, and with a maximum molecular stretch of $\lambda_{m} \cong 8.7$ and $\lambda_{m} \cong 12.1$ for PS-864/4k-33 and PS-864/4k-17, respectively, this results in $\sigma_{c}=2.7 \times 10^{8} \mathrm{~Pa}$ for PS-864/4k-33, and $\sigma_{c}=9.9 \times 10^{7} \mathrm{~Pa}$ for PS-864/4k-17, which is more than an order of magnitude larger than the stress at rupture observed experimentally (see Fig. 1).

From Fig. 1, it is obvious that the enthalpic fracture hypothesis cannot explain stress and strain of rupture for the monodisperse PS solutions investigated and that alternate explanations such as the entropic fracture hypothesis are needed. However, we agree with Wang [1] that cohesive fracture of polymer solutions and melts is caused by chain scission. As concluded in [2], we expect a crossover from the fracture criterion of well-cured rubbers to the fracture of polymer melts and solutions: For rubbers with $N_{x K} \leq$ $N_{e M}$, where $N_{x K}$ is the number of Kuhn steps between two cross-links and $N_{e M}$ is the number of Kuhn steps in an entanglement segment of the corresponding melt, the maximal molecular stretch is $\lambda_{m} \cong N_{x K}^{1 / 2}$, which is usually less than 6 , and fracture does not occur by thermal fluctuations but when the tension in the chain exceeds the rupture force of $\mathrm{C}-\mathrm{C}$ bonds (enthalpic fracture). On the other hand, for polymer gels, melts, and solutions with maximal molecular stretch $\lambda_{m} \cong\left(N_{e M} \varphi^{-1}\right)^{1 / 2} \geq 6$, the stretch at rupture is limited by thermal fluctuations (entropic fracture) to $f_{c}=\sqrt{U / 3 k T} \cong 6$, which represents an upper limit for the critical stretch at rupture for both entangled polymer liquids and elastomers. We found that entropic fracture of polymer liquids with maximal stretch $\lambda_{m}<9$ is influenced by finite extensibility effects [2], as the $\mathrm{C}-\mathrm{C}$ bonds are stretched and therefore the energy required for chain scission is reduced, and these polymer liquids fracture at a critical molecular stretch $f_{c}<6$.

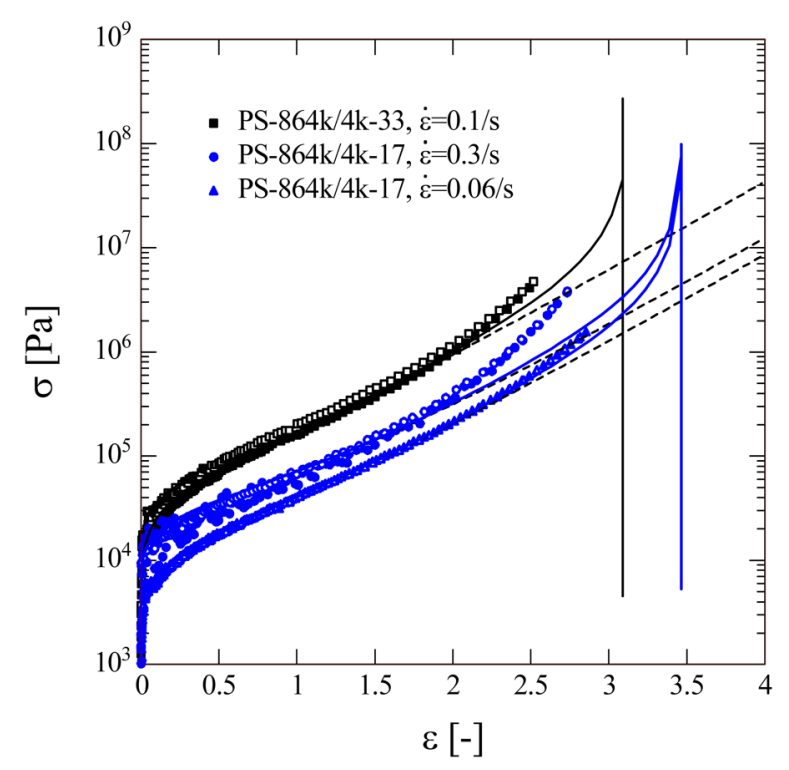

FIG 1. Experimental data (symbols) of true stress $\sigma$ as a function of Hencky strain $\varepsilon$ for solutions PS-864k/4k-33 and PS-864k/4k-17 [2]. Predictions (lines) according to the enthalpic fracture hypothesis with rupture stress $\sigma_{c}$ given by Eq. (5). 


\section{REFERENCES}

[1] Wang, S.-Q., "Letter to the Editor: Melt rupture unleashed by few chain scission events in fully stretched strands," J. Rheol. 63, 105-107 (2018).

[2] Wagner, M. H., E. Narimissa, and Q. Huang, "On the origin of brittle fracture of entangled polymer solutions and melts," J. Rheol. 62, 221-233 (2018).

[3] Rasmussen, H. K., and O. Hassager, "Reply to: 'On the "viscosity overshoot' during the uniaxial extension of a low density polyethylene,", J. Nonnewton Fluid Mech. 106, 171-172 (2012).

[4] Huang, Q., M. Mangnus, N. J. Alvarez, R. Koopmans, and O. Hassager, "A new look at extensional rheology of low-density polyethylene," Rheol. Acta 55, 343-350 (2016).
[5] Huang, Q., N. J. Alvarez, A. Shabbir, and O. Hassager, "Multiple cracks propagate simultaneously in polymer liquids in tension," Phys. Rev. Lett. 117, 087801 (2016).

[6] Huang, Q., and O. Hassager, "Polymer liquids fracture like solids," Soft Matter 13, 3470-3474 (2017).

[7] Pearson, D. S., A. D. Kiss, L. J. Fetters, and M. Doi, "Flow-induced birefringence of concentrated polyisoprene solutions," J. Rheology 33, 517-535 (1989).

[8] Zhurkov, S. N., and V. E. Korsukov, "Atomic mechanism of fracture of solid polymers," J. Poly. Sci. Part B Polym. Phys. 12, 385-398 (1974). 